\title{
Video Gaming As A Gendered Pursuit
}

Jenna M. Drenten

Loyola University Chicago, jdrenten@luc.edu

Robert L. Harrison

Nicholas J. Pendarvis

Follow this and additional works at: https://ecommons.luc.edu/business_facpubs

Part of the Business Commons, and the Gender, Race, Sexuality, and Ethnicity in Communication Commons

Author Manuscript

This is a pre-publication author manuscript of the final, published article.

\section{Recommended Citation}

Drenten, Jenna M.; Harrison, Robert L.; and Pendarvis, Nicholas J.. Video Gaming As A Gendered Pursuit. Handbook of Research on Gender and Marketing, , : 17, 2019. Retrieved from Loyola eCommons, School of Business: Faculty Publications and Other Works,

This Book Chapter is brought to you for free and open access by the Faculty Publications and Other Works by Department at Loyola eCommons. It has been accepted for inclusion in School of Business: Faculty Publications and Other Works by an authorized administrator of Loyola eCommons. For more information, please contact ecommons@luc.edu. c) $($ () $\ominus$

This work is licensed under a Creative Commons Attribution-Noncommercial-No Derivative Works 3.0 License. (c) Edward Elgar Publishing 2019 
Drenten, Jenna, Robert Harrison, and Nicholas Pendarvis (2019), "Video Gaming as a Gendered Pursuit," Handbook of Research on Gender and Marketing, Susan Dobscha (ed.), Edward Elgar Publishing, 28-44.

Note: This is a preprint version. The final published version of the paper may reflect notable format and content changes.

\title{
VIDEO GAMING AS A GENDERED PURSUIT
}

\author{
Jenna Drenten, Loyola University Chicago, USA \\ Robert Harrison, Western Michigan University, USA \\ Nicholas Pendarvis, California State University Los Angeles, USA
}

\begin{abstract}
As video game technology has evolved, so too has the gendered nature of the video gaming subculture. This chapter characterizes the broad cultural context of gaming and the shifting social patterns of gendered game play. By reviewing existing research at the intersection of gender, gaming, and consumption, we identify three primary research opportunities to build upon existing research: understanding consumers' lived experiences in the gendered gaming subculture, exploring the gendered gaming marketplace (e.g., shopping, advertising), and investigating the systemic, structural, and cultural underpinnings of gaming. Existing research in the field is not exhaustive nor complete; rather, opportunities for research identify gaps that should be examined more fully by building on existing foundational research. We also address potential challenges of conducting gender-based research in the context of gaming
\end{abstract}

KEYWORDS: video games, gamer culture, GamerGate, women in gaming, online harassment, video game advertising 


\title{
VIDEO GAMING AS A GENDERED PURSUIT
}

\author{
Jenna Drenten, Loyola University Chicago, USA \\ Robert Harrison, Western Michigan University, USA \\ Nicholas Pendarvis, California State University Los Angeles, USA
}

\section{INTRODUCTION}

The first mass-produced video arcade game, Computer Space, was released in 1971, followed by Atari Inc.'s famous Pong in 1972 (Kent, 2010). Today, consumers can play a range of technologically advanced video games from the comfort of their own living rooms. In fact, $63 \%$ of U.S. households own a device to play video games and $48 \%$ own a dedicated gaming console (Entertainment Software Association, 2016). Certainly, the technology upon which video games are built continues to evolve; however, the same cannot be said for the gendered underpinnings within the gaming subculture. Since 2008, the percentage of female gamers in the U.S. has consistently hovered at or above $40 \%$, reaching 48\% in 2014 and most recently 41\% in 2016 (Statista, 2017). While gender representation in gaming is reaching an equilibrium, inherent sexism and misogyny remains deeply embedded in the gaming community (Charles, 2016). Understanding the significance and role of gender in the gaming subculture is imperative in gaming research. This chapter explores the current state of gender and gaming research and identifies potential directions for consumer researchers to advance the conversation.

To understand the evolution of gender in video gaming, we must first appreciate the evolution of gaming itself. The dominant myth of technology asserts that "men design systems and women use them, men build bridges and women cross them" (Oldenziel 2001, p. 128). For example, home technologies like washing machines and stoves were created by men for women to use, but only in fulfillment of their traditional feminine gender roles. Women shaped technology as operators (e.g., telephone switchboard operators) and innovators (e.g., computing ballistic missile trajectories) throughout the early 1900s; yet, machine-based technology remained ensnared as a marker of masculine identity (Herzig, 2008). As Bray (2007) asserts in her review of feminist technology studies (FTS), gender and technology are coproduced and socially constructed.

Early gaming reproduced traditional gender roles. The first mechanized arcade games largely reflected masculine pastimes, such as hunting (Duck Hunt, 1969) and car racing (Grand Prix, 1969). Electronic arcade games followed suit by reproducing perceivably masculine content, with games like Space Invaders (1978) and Battlezone (1980). Throughout the 1970s and 1980s, arcades were a sanctuary of independence and socialization for adolescents (Panelas, 1983), particularly among boys (Kaplan, 1983). Rather than take up the controllers themselves, girls watched boys play and may have been deterred by action-packed, aggressive games (Kiesler, Sproull, \& Eccles, 1985). Personal video game consoles changed the gaming landscape by moving the experience from public arcades to private living rooms. Yet, gender bias in video game content and gameplay persisted (Gailey, 1993). 
Early at-home gaming systems like Atari and Colecovision in the 1970s paved the way for the iconic consoles in the late 1980s, like the Nintendo Entertainment System, Nintendo Gameboy, and Sega Genesis (Greenberg et al., 2010). Nineties gaming research suggests boys played video games more frequently than girls, but both sexes showed equal interest in playing (Colwell, Grady, \& Rhaiti, 1995; Gailey, 1993). Personal consoles brought gaming into the home, which is a traditionally feminine space (Attwood, 2005; Moisio, Arnould, \& Gentry, 2013). Still, the practice continued to skew toward a perceived masculine domain. In homes with coed siblings, brothers took control of the gaming system (McNamee, 1998) and parents reported purchasing consoles for their sons more than daughters (Gailey, 1993). Advances in visual design and 3D graphics gave rise to increasingly realistic, ultra-violent, highly sexual video games. In the United States, Congressional Hearings were held in response to video games like Mortal Kombat and Night Watch, which displayed violence and sexual exploitation. The hearings resulted in the formation of the Entertainment Software Ratings Board (ESRB), a self-regulated agency that assigns ratings to video games based on age-appropriateness, content, and interactivity.

At the turn of the century, the ESRB's age ratings became increasingly important as video games moved to the Internet. Gaming was no longer a pastime for children and adolescents alone. Adults flocked to online video games, which allowed them to play in a virtual social setting through Local and Wide Network (LAWN) Games and Massively Multiplayer Online Role-playing (MMORP) Games (Griffiths, Davies, and Chappell, 2003). The Internet ushered in promises of democratization, empowerment, and social community (Berthon, Holbrook, \& Hulbert, 2000; Cova \& Pace, 2006)—suggesting a potential shift toward a more gender fluid gaming subculture. However, throughout the 2000 s, video gaming content and marketing continued to reflect a masculine leisure activity (Dill \& Thill, 2007; Ivory, 2006; Near, 2013). Today, there are an average of 1.7 gamers in every U.S. household (Entertainment Software Association, 2016). Multiplayer online games continue to be popular among consumers, along with a rise in mobile games and virtual reality.

The purpose of this chapter is to characterize the broad cultural context of gaming and the shifting social patterns of gendered game play. Our chapter focuses on cultural meanings and gendered practices embedded within gaming. Of note, we are specifically concerned with understanding traditional video gaming (e.g., in-home consoles) practices rather than more modern evolutions in gaming, such as mobile gaming. By reviewing existing research at the intersection of gender, gaming, and consumption, we identify opportunities for future research and address potential challenges of conducting genderbased research in the context of gaming. Existing research in the field is not exhaustive nor complete; rather, opportunities for research identify gaps that should be examined more fully by building on existing foundational research.

\section{TOWARD A CULTURAL PERSPECTIVE OF GENDER AND GAMING}

We begin by exploring the current state of gender and gaming research and identifying potential directions for consumer researchers to advance the conversation. Cassell and Jenkins' (1998) book, From Barbie to Mortal Kombat: Gender and Computer Games, marks one of the first efforts to adapt academic research on gender and gaming 
for a mainstream audience. Covering topics such as the emergence of a "girl games" market and the gendering of technology, their work helped bolster the importance to gender and gaming scholarship in everyday consumers' lives. Relevant to understanding gaming as a gendered pursuit in the marketplace, we identify three primary research opportunities to build upon existing research: understanding consumers' lived experiences in the gendered gaming subculture, exploring the gendered gaming marketplace (e.g., shopping, advertising), and investigating the systemic, structural, and cultural underpinnings of gaming. To contextualize each of these future opportunities within the existing literature, we review relevant existing research at the intersection of gaming, gender, and consumer research.

\section{Research Opportunity \#1:}

- Current research focuses on dichotomous gendered representations in gaming content.

- Future research should examine intersectional gendered representations in gaming content as it relates to lived consumer experiences.

Established research explores gendered content in video games, with an emphasis on video game characters and actions within each game. Tucker (2011) suggests video games are "intersections of sports and technology where masculinity is constructed and reinforced" and as such, they produce "very limited notions of gender, reinforcing the sexual objectification of women" (p. 9). Women are overwhelmingly underrepresented in video game content, erring on the side of systematically over-representing male characters (Williams, Martins, Consalvo, \& Ivory, 2009). When women are featured, they play the stereotypical role of 'damsel in distress,' are the virtual recipients of violent aggressions (e.g., raping a female prostitute in Grand Theft Auto), or are designed as sex objects with little clothing and enhanced figures (Beasley \& Collins-Standley, 2002; Burgess, Stermer, \& Burgess, 2007; Dill \& Thill, 2007; Downs and Smith, 2010; Ivory, 2006; Jansz \& Martis, 2007; Summers \& Miller, 2014). This is particularly concerning when considering the internalized effects of such sexualized or sexist representations. Fox, Bailenson, \& Tricase (2012) find gamers who use sexualized characters experience more body-related, self-objectifying thoughts than those using non-sexualized characters. Violent-sexist video games increase traditionally masculine beliefs and reduce empathy for female violence victims in video games (Gabbiadini, Riva, Andrighetto, Volpato, \& Bushman, 2016). Taken together, existing research demonstrates ways in which gender stereotypes and ideologies are produced and reproduced through the content of video games. That is, men are dominant aggressors and women are submissive objects in the pursuit of masculinity.

Indeed, the content in video games relies heavily on gender stereotypes and heteronormative views. Most relationships between video game characters are heterosexual in nature; however, video game content is slowly—very slowly-becoming more inclusive of gender fluidity and sexual orientations (Shaw, 2017). Thus, it is important that researchers monitor changing, or unchanging, gender issues related to heteronormative gender roles, gender fluidity, and consumer identity in gaming. In Tucker's (2011) study of 'griefing,' or trolling behaviors in gaming, she concludes video games reinforce hegemonic masculinity by through virtual experiences of aggressive 
violence, graphic language, and sexual domination. Despite gaming's roots in misogyny and toxic masculinity, it offers opportunities to instigate change. For example, in 2017, Momo Pixel, an African-American female artist, created a game called Hair Nah!, in which the main character, a woman of color, must get to the airport on-time while swatting away Caucasian hands attempting to touch her hair (Gray, 2017). The game reflects microagressions that Pixel and fellow women of color experience in their daily lives. Researchers should further explore how gaming content and production propagates or contests existing gender perspectives. Moreover, they should push further to understand gender as it intersects with other marginalized positions in society based on class, race, and age, among others. For instance, PewDiePie, a 27-year-old male gamer from Sweden with over 50 million YouTube followers, stirred controversy for using racist slurs and antiSemetic language in his online videos and livestreams of gaming. As a white, cisgender male gamer, PewDiePie's displays of hatred and dominance are emboldened by the undercurrent of patriarchy within the gaming genre (Mac, 2017).

Research is needed to update our understanding of gaming content, beyond the gender binary (e.g., male versus female representations), and to explore how consumers experience gender through gaming experiences. Advances in gaming technology, particularly online in-game communication in the area of multiple player gaming, has increasingly become a source of gender discrimination (McLean \& Griffiths, 2013). Harassment issues have an effect on gaming experiences and identity, as research suggests that players will often conceal their gender identity (via gender swapping, or playing as the opposite gender) in order to avoid harassment. For example, players who identify as female may choose masculine avatars in video games to cope with harassment (Hussain \& Griffiths, 2008). Rather than expressing gender equality, dominant presence of masculine identities in gaming replicates gender-based silencing and harassment present in off-line spaces (Guzzetti, 2008). Future research should investigate the impact of gender concealment and other gendered practices in gaming culture. On one hand, identity masking though subversive, is counter-productive to those who view visibility as necessary for disrupting gender normality. This dialectical tension between gender visibility and online harassment/safety concerns represents a fundamental difference in female gaming experience goals. For some this is the game; for others, it is a barrier to gaming. To overcome harassment, female gamers may prefer playing with friends versus playing with people they have never met. Do females experience harassment or in-game bullying when playing with friends? We know from recent research that playing video games with a sibling is associated with higher levels of sibling affection for both boys and girls, but higher levels of conflict for boys only (Coyne, Jensen, Smith, \& Erickson, 2016). Is that the case with friends? On the other hand, the fluidity of gender in gaming may offer opportunities for consumers to explore a broad spectrum of gender identities. How might transgender players use gaming to cope with transitioning, or how might gaming experiences differ for non-binary consumers?

\section{Research Opportunity \#2:}

- Current research focuses on gendered content featured in gaming-related marketing and advertising. 
- Future research should examine gendered experiences in the marketplace, such as shopping for gaming-related products.

The gendered marketing of video games has long been of interest to scholars. Kaplan (1983) compared early arcade video games to pinball machines and found that arcade video games had less sexualized exterior designs than pinball machines. He posited arcade video games did not need to use sex appeals because they were inherently alluring, versus pinball machines. However, with the increased popularity of personal consoles, video game advertising historically features violence, sexualization, and gender stereotypes (Scharrer, 2004). Video game advertisements in magazines consistently depict women in demeaning and subjugating ways (Dill \& Thill, 2007; Scharrer, 2004). Female characters are rarely depicted in video game advertisements, and when depicted they are often portrayed as curvaceously thin, dressed in tight or provocative clothing, and display sexually suggestive postures and facial expressions (e.g., licking their lips, bending over; Scharrer, 2004). Research also suggests that articles in video game magazines and on video game covers portray women in the same objectifying ways as advertisements (Burgess, Stermer, \& Burgess, 2007; Miller \& Summers, 2007). Recent research continues to explore how gender is represented in the marketing of video games, beyond advertising media. Near (2013) demonstrates that video game boxes with sexualized female characters have the highest sales for teen- and mature-rated video games. The study concludes gender stereotypes, such as objectified women and aggressive men, are commonly depicted in video game marketing (e.g., game boxes) to reinforce hypermasculinity existing in culture; "in other words, a masculine-coded space signals potential buyers that the game will meet the cultural norms for this type of game space" (Near, 2013, p. 13). Research also explores how gamers are represented physically in commercial advertising. Drawing on a content analysis of video game commercials in 2013, Chess, and colleagues (2017) found some evidence of increased diversity (e.g., multiple ethnicities, co-ed gaming groups) and decreased sexualization in gaming commercials. Although game advertising is slowly pivoting toward diversity among gamers, it continues to primarily feature white males and sexualized women.

Future research should provide a better understanding of other experiential aspects of video game marketing, specifically the shopping experience itself. Harrison, Drenten, and Pendarvis (2016) discuss the experience of gender biases in the process of purchasing video games. Females in their study reveal the anxiety felt when visiting video game retailers because they are often treated as "inauthentic" gamers, who are shopping exclusively for boyfriends. More research is needed to better understand video game shopping as a gendered experience. Traditional theories describe shopping as "a labor of love" and as a female experience (Miller, 1998). Research also suggests that males experience gender-role identity conflict while shopping (Otnes \& McGrath 2001; Tuncay \& Otnes 2008). The gaming context may offer unique insights into the gender-role conflict that shopper's experience. Much of the work to date falls back to the male-female dyad. For instance, Alpert and Saxton (2015, p.312) manipulated video game advertisements targeted toward men versus women for a hypothetical strategy game. Using stereotypical assumptions from previous sex-based gaming studies, the male-oriented advertisement used words like "intense combat" and "battle," while the female-oriented advertisement 
used words like "build relationships" and "create a community." To the authors' surprise, such dichotomous gender stereotyped advertising was not as effective as expected. Instead, gamers prefer high quality, multidimensional games, transcendent of genderbased stereotypes.

In addition, research should continue to monitor, not only how gender is depicted in video game advertising, but also the intersection of gender, race, class and other cultural conventions in gaming advertising. For example, Behm-Morawitz (2017) found support for the reliance on stereotypic portrayals of the White male hero, submissive sexualized female, Asian ninja, deviant Black male, and invisible Black female when race and ethnicity intersects with gender in gaming advertisements. She calls for future research to advance an intersectionality approach and to examine the short and long-term impacts these stereotypical depictions have on gaming culture. Researchers should also take a transformative consumer research approach to update our understanding of consumer well-being as they respond to video game marketing. Beyond content analyses of representations of gender in video game marketing, little research to date systematically examines the gendered marketing of video games from a cultural perspective. One notable exception is Chess's (2011) study of advertising for Nintendo DS and Nintendo Wii in women's special interest magazines. Some advertisements target mothers who could use gaming to bond with their children while others emphasize productivity through gaming (Chess, 2011). As Chess (2011) notes, "By collapsing play with productivity, there is something larger being sold about how women are expected to play. In turn, video games are able to maintain status as masculine play spaces, reinforcing subtext that women should only play in specific circumstances" (p. 236). More research should explore the cultural underpinnings and symbolic interpretations of video game marketing, from the perspective of the consumer.

\section{Research Opportunity \#3:}

- Current research focuses on individual gender differences and micro-level perspectives of gaming.

- Future research should examine structural, cultural, and macro-level actors as they influence gaming experiences.

Previous research on gender and gaming largely addresses individual gender differences (Gabbiadini, Rive, Andrighetto, Volpato, \& Bushman, 2016; Veltri, Krasnova, Baumann, \& Kalayamthanam, 2014). For instance, males use virtual worlds more than females (Becerra \& Stutts, 2008) and are more likely to partake in virtual gender switching (i.e., use an avatar of the opposite sex; Hassouneh \& Brengman, 2014). Researching gender differences can be tempting but limiting. Exploring gender differences alone can lead to unfair stereotypes, while a gender similarities perspective may ignore nuance in the gendered experience. Muehlenhard (2000) advocates for research exploring both gender differences and gender similarities. Moreover, this type of he-does-this and she-does-that research does little to advance our theoretical understanding of the gendered consumption experience of gaming. Indeed, most research on gender and gaming examines the individual consumer experience and does not consider social-structural constraints or opportunities (Martin \& Rafalow, 2015). Research is beginning to recognize gender biases 
in gaming may result from factors beyond micro-level consumer experiences. For instance, gender portrayals in gaming content are embedded within the industry itself. Shaw's (2009) study of game developers suggests the gaming industry culturally reproduces

heteronormative gender expectations for fear of consumer backlash coupled with a lack of diverse gender representation among video game designers. As one game developer in Shaw's (2009) study states, "We're barely at the point where people can convey emotions through characters. It's easier for developers to rely on stereotypes and/or archetypes for now" (p. 244). Further, gender issues in the gaming community may be endemic of gender issues in society. Research should investigate how gaming, through stereotypical representations, messages, and behaviors, exacerbates or perpetuates a misogynistic culture, as well as how public policies could improve general public welfare.

Understanding the structural, top-down influences (e.g., public policies, industry factors, cultural values) that shape the gaming market are critical for understanding gaming as a gendered pursuit. Macro-level research may also consider how traditional gaming concepts are seeping into consumers daily lives through gamification practices, such as tracking one's steps and competing with friends via FitBit (see Dymek \& Zackariasson 2016). To date, gamification research largely ignores gender as a social construct, opting instead to document sex differences. Feminist and gender scholars might contribute to our understanding of gamification and its broad implications for reproducing or contesting gender ideals.

Researchers should view gender issues in gaming as structural, sociocultural phenomena. A cultural perspective reshapes how gender issues are perceived, as Jenson and de Castell (2013, p. 73) argue:

"Positioning women as precarious subjects-and objects—in videogame culture, shifts the ground from the individual case of a single woman being harassed while speaking and playing in an online game, or when simply writing or blogging about games, to a structural level that ties in with social and cultural gender norms, as well as with political and legal structures that have yet to come 'online' to offer real protection from."

This cultural view, that gender norms are inseparable from the circulation of larger power dynamics, should inform future research investigating the struggle over power and the maintenance in videogame culture. More specifically, scholars should investigate issues of political and power structure within the gaming community. Participants in Harrison, Drenten, and Pendarvis's research (2016) described feeling hopeless against gaming harassment. While online harassment continues to be a concern for female gamers, in particular, an industry poll found many online gaming service providers were unwilling to discuss concerns of harassment and abuse and subsequent banning procedures (Campbell, 2016). Future research should explore how the gaming community polices or propagates such harassment. For example, consumers have resorted to creating online discussion forums that list the names of gamers to avoid, or creating private gaming groups to avoid malicious gamers.

In addition, game developers are beginning to monitor abuse claims all in efforts to circumvent inadequate service provider policing procedures. Massanari (2017) dubs Reddit a "toxic technoculture" and suggests its governance, policies, and community users contributed to the rise of GamerGate, an anti-feminist movement meant to discredit and 
undermine female and minority gamers and their allies (e.g., journalists, game developers). The author suggests GamerGate is a reflection of larger problematic issues with 'geek masculinity.' At the industry level, research should further examine gender and intersectionality in the gaming industry itself. Unsurprisingly, there is a shortage of female game developers and designers. However, there have been strategic efforts in the indie gaming community to make the industry more attractive to potential female students through the creation of women-only workspaces and awarding scholarships to game design schools (Fisher \& Harvey, 2013). The International Game Developers Association suggests that only 3 percent of game developers are African-American, a figure that has risen by only 0.5 percent in the past decade. In comparison, 76 percent of developers are white. In line with Shaw (2009), research should investigate gendered industry experiences in both the traditional and indie gaming environment.

\section{BARRIERS TO RESEARCHING GENDER AND GAMING}

Capturing the emic experiences of consumers in the context of online gaming and gaming communities presents a unique set of challenges. Traditionally, ethnography captures aspects of culture in its "most complex whole" by allowing researchers to create thick description - involving a combination of participant and non-participant observation, in-depth interviews, and varied forms of textual analysis (Geertz, 1973). From an anthropological perspective, textual analysis of relevant historical or archival texts has typically added supplemental value to the analysis of field notes and interview transcripts that typically yields richer cultural insight. Nevertheless, contemporary research on subcultures of consumption, collaborative consumer networks, and consumption communities have demonstrated that these collectives often have a significant presence in both the real world as well as on the internet in the form of online chat forms, discussion boards, and designated social networks. As such, online texts have become an increasingly important cultural resource in studying how culture operates in the age of the internet; however, researchers must strike the appropriate balance between traditional methods and novel approaches to data collection and analysis while not compromising the quality of the data.

Researchers studying contemporary culture across a number of disciplines advocate for studying technology-mediated social behavior across online and offline contexts for more meaningful insights (Wilson, 2006; Hine, 2000). Accordingly, it is necessary to acknowledge the ways in which consumers in online gaming communities engage one another across a wide range of online platforms as well as in various offline contexts. For gamers, online interactions take on a particularly significant role in the experiences and social lives of gaming community members (Nardi \& Harris, 2006). For researchers studying gender in the gaming world, recording accurate representations of this discursive behavior becomes paramount to understanding how aspects of meaning and identity are socially constructed in this space.

Adding to the complexity of understanding gender and video game culture more broadly is the private nature of online gaming. That is, while gaming itself has become a highly social endeavor, the bulk of social interaction takes place in the virtual confines of online gaming services like Xbox Live or in online community discussion forums (Nardi, Ly, 
\& Harris, 2007). For many players, the act of gaming itself often takes place in private settings, where players are physically isolated from other individuals. For some members of the community, this separation is intentional as gaming is associated with escapism and players often aim to dissociate their online persona from their actual identity and the roles they play in other social domains (Kuss, Louws, \& Wiers, 2012). The notions of escapism and anonymity that are prevalent in gaming culture may at times result in some gamers being reluctant to talk openly about their experiences. As such, traditional usage of observation techniques and in-depth interviews may be viewed as intrusive by gaming community members. Moreover, given the sensitive nature of gender relations within gaming culture alternative methods for collecting data would likely be necessary to generate useful insight.

In order to accurately capture the nature of both the online and offline experiences of consumers in gaming communities, researchers must rely upon qualitative data from a broad range of sources while giving primacy to forms of data that would traditionally be deemed ancillary. In the context of gaming, this specifically calls for relying more heavily on netnographic data collection techniques that include qualitative textual analysis of relevant discourse in online gaming forums in a manner similar to techniques applied in consumer research on analogous online/offline contexts (Kozinets, 1999, 2002; Kozinets \& Handelman, 2004).

As noted, respecting the privacy of gamers should be of primary concern to those studying this context. Fortunately, the public nature of most internet forums offers researchers an ethically sound window into gaming culture that does not come across as invasive or disruptive to the subjects being studied. Prior research has relied upon data collected from online discussion communities and chat forum websites that are open to the public. As with other online communities studied in consumer research, participants in these gaming-oriented online discussion communities range from the highly-active "core insiders," who tend to occupy more opinion leadership and avant-garde roles in the community; to more casual "minglers" and "tourists" whose participation in discussion is less consistent and engaged (Kozinets, 1999, 2002). These kinds of distinctions in online community membership are important for studying gender in this context as women's individual goals and motivations to play have been shown to vary according to level of involvement (Royse et al., 2007). Thus, special attention should be given to capturing the full range of participant discussions in order to avoid the likelihood of studies being misinformed by marginal discourse or unrepresentative content. Moreover, carefully sorting and selecting online discourse in netnography is described as being somewhat analogous to "purposive sampling" in market-oriented ethnography (Kozinets, 2002, p. 67; Lincoln \& Guba, 1990; Wallendorf \& Belk, 1989).

While qualitative analysis of online text can be particularly informative in studying video game subculture, it is not a complete substitute for the cultural insight gleaned from the observation of actual behavior. As in all cultures, there may be significant discrepancies in what people actually do and how it is described in cultural texts. It may be useful to supplement netnographic data collection with more innovative forms of participant and non-participant ethnographic observations. Meades (2013) study of emergent culture surrounding the illicit use of software modification (i.e., "hacking") in the Call of Duty (CoD) online gaming community offers a unique methodological approach to participant and non- 
participant observation in an online gaming community. The author began by establishing an online account with an online gaming service provider and creating a unique online identity (i.e., "gamer tag") for the sole purpose of collecting ethnographic data via participant observation. Meades gains entrée into the Call of Duty community by establishing relationships with other $\mathrm{CoD}$ players. He then uses those relationships and experiences to develop an initial understanding of the community's norms and vocabularies, while familiarizing himself with the mechanics of actual gameplay. In similar studies, researchers engaged in ongoing experiential immersion through field research within video game communities engaging in regular gameplay and participating in local offline events that are regularly attended by community members (e.g., small informal inhome tournaments, annual midnight sales/launch events; Chee, 2005). In other studies, live streaming and social networking services (e.g., Twitch) were used to simultaneously view live broadcasts of national and international professional gaming tournaments on the official Major League Gaming (MLG) channel and interact with other members of the community (e.g., Hamilton, Garretson, \& Kerne, 2014; Kaytoue et al., 2012). In sum, these approaches to observation allow scholars to develop a rich emic account of the community practices of interest in situ, provide the opportunity for data triangulation, and ultimately support the development of richer theory.

\section{CONCLUSION}

The constructs of sex and gender are fundamentally distinct (Fischer \& Arnold, 1994). Sex is a biological category; whereas gender constitutes a collection of characteristics associated with femininity and masculinity (Fischer \& Arnold, 1994; Muehlenhard, 2000; Palan, 2001). Despite the necessary distinction between sex and gender, the two are often conflated in gaming research. For instance, Lucas and Sherry (2004) explore how gender roles shape male versus female players' motivations and preferences in video gaming; however, the authors use the terms sex and gender interchangeably. Moreover, as we discuss, the gaming industry largely ignores variations in gender beyond the binary male/female perspective (Shaw \& Friesem, 2016). In examining the intersection between gender and gaming, we acknowledge the challenge of disconnecting gender from sex in previous gaming research, and we call for future scholars to turn an acute eye toward understanding gaming as a gendered pursuit. As gaming increasingly attracts a diverse audience, it is important for marketing scholars to better understand the gamers' marketplace experiences through the lens of gender. More specifically, we identify three primary streams of future research relevant to understanding gaming as a gendered pursuit in the marketplace: understanding consumers' lived experiences in the gendered gaming subculture, exploring the gendered gaming marketplace (e.g., shopping, advertising), and investigating the systemic, structural, and cultural underpinnings of gaming. Previous research is valuable from an operational perspective but largely fails to capture consumers' lived experiences in the context of cultural norms and institutional systems. By understanding how the gendered gaming subculture is created, consumed, and contested, consumer researchers may be able to advance public policy and marketing to improve consumer well-being. 


\section{REFERENCES}

Alpert, F., \& Saxton, M. K. (2015). Can multiple new-product messages attract different consumer segments? Journal of Advertising Research, 55(3), 307-321.

Attwood, F. (2005). Inside out: Men on the 'home front'. Journal of Consumer Culture, 5(1), 87-107.

Beasley, B., \& Collins-Standley, T. (2002). Shirts vs. skins: Clothing as an indicator of gender role stereotyping in video games. Mass Communication \& Society, 5(3), $279-93$.

Becerra, E. P., \& Stutts, M. A. (2008). Ugly duckling by day, super model by night: The influence of body image on the use of virtual worlds," Journal of Virtual Worlds Research, 1(2), 1-19.

Behm-Morawitz, E. (2017). Examining the intersection of race and gender in video game advertising. Journal of Marketing Communications, 23(3), 220-239.

Berthon, P., \& Holbrook, M. B. (2000). Beyond market orientation: A conceptualization of market evolution. Journal of Interactive Marketing, 14(3), 50-66.

Bray, F. (2007). Gender and technology. Annual Review of Anthropology, 36, 37-53.

Burgess, M. C. R., Stermer, S. P., \& Burgess S. R. (2007). Sex, lies, and video games: The portrayal of male and female characters on video game covers. Sex Roles, 57(5-6), 419-33.

Campbell, C. (2016). How are games companies dealing with online abuse. Polygon, Retrieved on April 2, 2017 from http://www.polygon.com/2016/7/22/12256114/how-are-games-companies-dealingwith-online-abuse.

Cassell, J., \& Jenkins, H. (1998). From Barbie to Mortal Kombat: Gender and computer games. Cambridge, MA: MIT Press.

Charles, C. (2016). Keeping quiet: Investigating the maintenance and policing of maledominated gaming space. Electronic Theses and Dissertations. 5115. http://stars.library.ucf.edu/etd/5115

Chee, F. (2005). Understanding Korean experiences of online game hype, identity, and the menace of the 'Wang-Tta'. Popular Communication, 4(3), 225-239.

Chess, S. (2011). A 36-24-36 cerebrum: Productivity, gender, and video game advertising. Critical Studies in Media Communication, 28(3), 230-52.

Chess, S., Evans, N. J., \& Baines, J. J. (2017). What does a gamer look like? Video games, advertising, and diversity. Television \& New Media, 18(1), 37-57.

Colwell, J., Grady, C., \& Rhaiti, S. (1995). Computer games, self-esteem and gratification of needs in adolescents. Journal of Community \& Applied Social Psychology, 5(3), 195206.

Cova, B., \& Pace, S. (2006). Brand community of convenience products: New forms of customer empowerment-the case 'My Nutella the Community'. European Journal of Marketing, 40(9/10), 1087-105.

Coyne, S. M., Jensen, A. C., Smith, N. J., \& Erickson, D. H. (2016). Super mario brothers and sisters: Associations between coplaying video games and sibling conflict and affection. Journal of Adolescence, 47, 48-59.

Dill, K. E., \& Thill, K. P. (2007). Video game characters and the socialization of gender roles: young people's perceptions mirror sexist media depictions. Sex Roles, 57(11-12), 851-64. 
Downs, E., \& Smith, S. L. (2010). Keeping abreast of hypersexuality: A video game character content analysis," Sex Roles, 62(11-12), 721-33.

Dymek, M., \& Zackariasson, P. (2016). The Business of Gamification: A Critical Analysis. London, UK: Routledge.

Entertainment Software Association (2016). 2016 essential facts about the computer and video game industry, accessed at: http://essentialfacts.theesa.com/Essential-Facts2016.pdf.

Fischer, E., \& Arnold, S. J. (1994). Sex, gender identity, gender role attitudes, and consumer behavior. Psychology \& Marketing, 11(2), 163-82.

Fisher, S., \& Harvey, A. (2013), "Intervention for Inclusivity: Gender Politics and Indie Game Development," Loading...Journal of the Canadian Game Studies Association, 7(11), 25-40.

Fox, J., Bailenson, J. N., \& Tricase, L. (2013). The embodiment of sexualized virtual selves: the proteus effect and experiences of self-objectification via avatars," Computers in Human Behavior, 29(3), 930-38.

Gabbiadini, A., Riva, P., Andrighetto, L., Volpato, C., \& Bushman, B. J. (2016). Acting like a tough guy: Violent-sexist video games, identification with game characters, masculine beliefs, \& empathy for female violence victims," PLoS one, 11(4), e0152121.

Gailey, C. W. (1993). Mediated messages: Gender, class, and cosmos in home video games. The Journal of Popular Culture, 27(1), 81-98.

Geertz, C. (1973). The Interpretation of Cultures. New York, NY: Basic Books.

Gray, D. (2017, November 17), "This woman made a video game to tackle people touching black women's hair without permission," Allure, retrieved from https://www.allure.com/story/hair-nah-stop-touching-black-womens-hair-videogame.

Greenberg, B. S., Sherry, J., Lachlan, K., Lucas, K., \& Holmstrom, A. (2010), "Orientations to video games among gender and age groups," Simulation \& Gaming, 41(2), 238-59.

Griffiths, M. D., Davies, M. N. O., \& Chappell, D. (2003). "Breaking the Stereotype: The Case of Online Gaming," CyberPsychology \& Behavior, 6 (1), 81-91.

Guzzetti, B. J. (2008). Identities in online communities: A young woman's critique of cyberculture. E-Learning and Digital Media, 5(4): 457-474.

Hamilton, W. A., Garretson, O., \& Kerne, A. (2014). Streaming on Twitch: Fostering participatory communities of play within live mixed media. In Proceedings of the 32nd Annual ACM Conference on Human Factors in Computing Systems: 1315-24.

Harrison, Robert, Jenna Drenten, and Nicholas Pendarvis (2016), "Gamer Girls: Navigating a Subculture of Gender Inequality," in Russell W. Belk, Diego Rinallo, and Nil Özçaglar-Toulouse (Eds.), Research in Consumer Behavior: Consumer Culture Theory (pp. 47-64), Vol. 18, Bingley, UK: Emerald Group Publishing Limited.

Hassouneh, D., \& Brengman, M. (2014). A motivation-based typology of social virtual world users. Computers in Human Behavior, 33, 330-38.

Herzig, R. (2008). Gender and technology. In Carroll Pursell (Ed.), A Companion to American Technology (pp. 199-211), Malden, MA: Blackwell Publishing.

Hine, C. (2000). Virtual Ethnography, Thousand Oaks, CA: SAGE Publications. 
Hussain, Z., \& Griffiths, M. D. (2008). Gender swapping and socializing in cyberspace: An exploratory study. CyberPsychology \& Behavior, 11(1), 47-53.

Ivory, J. D. (2006). Still a man's game: Gender representation in online reviews of video games," Mass Communication \& Society, 9(1), 103-14.

Jansz, J., \& Martis, R. G. (2007). The Lara phenomenon: Powerful female characters in video games. Sex Roles, 56(3-4), 141-48.

Jenson, J., \& De Castell, S. (2013). Tipping points: Marginality, misogyny and videogames. Journal of Curriculum Theorizing, 29(2), 72-85.

Kaplan, S. J. (1983). The image of amusement arcades and differences in male and female video game playing. The Journal of Popular Culture, 17(1), 93-98.

Kaytoue, M., Silva, A., Cerf, L., Meira Jr., W., \& Raïssi, C. (2012). Watch me playing, I am a professional: A first study on video game live streaming. In Proceedings of the $21 \mathrm{st}$ International Conference on World Wide Web: ACM, 1181-88.

Kent, S. L. (2010). The Ultimate History of Video Games: From Pong to Pokemon and Beyond-the Story Behind the Craze That Touched Our Lives and Changed the World. New York, NY: Three Rivers Press.

Kiesler, S., Sproull, L., \& Eccles, J. S. (1985). Pool halls, chips, and war games: Women in the culture of computing. Psychology of Women Quarterly, 9(4), 451-462.

Kozinets, R. V. (1999). E-tribalized marketing?: The strategic implications of virtual communities of consumption. European Management Journal, 17(3), 252-64.

Kozinets, R. V. (2002). The field behind the screen: Using netnography for marketing research in online communities. Journal of Marketing Research, 39(1), 61-72.

Kozinets, R. V., \& Handelman, J. M. (2004). Adversaries of consumption: consumer movements, activism, and ideology. Journal of Consumer Research, 31(3), 691-704.

Kuss, D. J., Louws, J., \& Wiers, R. W. (2012). Online gaming addiction? Motives predict addictive play behavior in massively multiplayer online role-playing games. Cyberpsychology, Behavior, and Social Networking, 15(9), 480-85.

Lincoln, Y. S., \& Guba, E. G. (1990). Judging the Quality of Case Study Reports. Internation Journal of Qualitative Studies in Education, 3(1), 53-59.

Lucas, K., \& Sherry, J. L. (2004). Sex differences in video game play: A communicationbased explanation. Communication Research, 31(5), 499-523.

Mac, R. (2017, September 11). YouTuber PewDiePie says racist remark during livestream. In BuzzFeed News, retrieved at https://www.buzzfeed.com/ryanmac/youtuberpewdiepie-says-racist-remark-duringlivestream?utm_term=.ycvN9OAJB\#.hxOxQZjpA.

Martin, C., \& Rafalow, M. (2015). Gendered barriers to participation in gaming culture. In Proceedings of the Third Conference on GenderIT: ACM, 49-52.

Massanari, A. (2017). \#Gamergate and the fappening: How Reddit's algorithm, governance, and culture support toxic technocultures. New Media \& Society, 19(3), 329-46.

McLean, L., \& Griffiths, M. D. (2013). Female gamers: A thematic analysis of their gaming experience. International Journal of Game-Based Learning (IJGBL), 3(3), 54-71.

McNamee, S. (1998). Youth, gender and video games: Power and control in the home," Cool places: Geographies of Youth Cultures, 195-206. 
Meades, A. F. (2013). Infectious pleasures: Ethnographic perspectives on the production and use of illicit videogame modifications on the Call of Duty franchise. Journal of Gaming \& Virtual Worlds, 5(1), 59-76.

Miller, D. (1998). A Theory of Shopping. Cambridge, UK: Blackwell Publishers Ltd.

Miller, M. K., \& Summers, A. (2007). Gender differences in video game characters' Roles, appearances, and attire as portrayed in video game magazine. Sex Roles, 57(9-10), 733-42.

Moisio, R., Arnould, E. J., \& Gentry, J. W. (2013). Productive consumption in the classmediated construction of domestic masculinity: Do-it-yourself (DIY) home improvement in men's identity work. Journal of Consumer Research, 40(2), 298-316.

Muehlenhard, C. L. (2000). Categories and sexuality. Journal of Sex Research, 37(2), 101-07.

Nardi, B., \& Harris, J. (2006). Strangers and friends: Collaborative play in World of Warcraft. In Proceedings of the 2006 20th Anniversary Conference on Computer Supported Cooperative Work, 149-158.

Nardi, B. A., Ly, S., \& Harris, J. (2007). Learning conversations in World of Warcraft. In 40th Annual Hawaii International Conference on System Sciences (HICSS): IEEE, 79-79.

Near, C. E. (2013). Selling gender: Associations of box art representation of female characters with sales for teen-and mature-rated video games. Sex Roles, 68(3-4), 252-69.

Oldenziel, R. (2001). Man the maker, woman the consumer. In Craeger, A., Lunbeck, E., and Schiebinger, L. (Eds.), Feminism in Twentieth-Century Science, Technology, and Medicine (pp. 128-148). Chicago, IL: University of Chicago Press.

Otnes, C., \& McGrath, M. A. (2001). Perceptions and realities of male shopping behavior. Journal of Retailing, 77(1), 111-137.

Palan, K. M. (2001). Gender identity in consumer behavior research: A literature review and research agenda. Academy of Marketing Science Review, 1-26.

Panelas, T. (1983). Adolescents and video games: Consumption of leisure and the social construction of the peer group. Youth \& Society, 15(1), 51-65.

Royse, P., Lee, J., Undrahbuyan, B., Hopson, M., \& Consalvo, M. (2007). Women and games: Technologies of the gendered self. New Media \& Society, 9(4), 555-576.

Scharrer, E. (2004). Virtual violence: Gender and aggression in video game advertisements. Mass Communication \& Society, 7(4), 393-412.

Shaw, A. (2017). What's next?: The LGBTQ video game archive. Critical Studies in Media Communication, 34(1), 88-94.

Shaw, A. (2009). Putting the gay in games: Cultural production and GLBT content in video games. Games and Culture, 4(3), 228-53.

Shaw, A., \& Friesem, E. (2016). Where Is the queerness in games?: Types of lesbian, gay, bisexual, transgender, and queer content in digital Games. International Journal of Communication, 10, 3877-3889.

Statista (2017). Distribution of computer and video gamers in the united states from 2006 to 2016 , by gender. Accessed at: https://www.statista.com/statistics/232383/gender-split-of-us-computer-and-videogamers/. 
Summers, A., \& Miller, M. K. (2014). From damsels in distress to sexy superheroes: How the portrayal of sexism in video game magazines has changed in the last twenty years. Feminist Media Studies, 14(6), 1028-40.

Tucker, S. (2011), Griefing: Policing masculinity in online games. (Master's thesis, University of Oregon). Retrieved from Proquest Dissertations Publishing, UMI: 1505169.

Tuncay, L., \& Otnes, C. C. (2008). The use of persuasion management strategies by identity-vulnerable consumers: The case of urban heterosexual male shoppers. Journal of Retailing, 84(4), 487-499.

Veltri, N., Krasnova, H., Baumann, A., \& Kalayamthanam, N. (2014). Gender differences in online gaming: A literature review. In Twentieth Americas Conference on Information Systems, Savannah, GA.

Wallendorf, M., \& Belk, R. W. (1989). Assessing trustworthiness in naturalistic consumer research. In SV - Interpretive Consumer Research, Provo, UT: Association for Consumer Research, 69-84.

Williams, D., Martins, N., Consalvo, M., \& Ivory, J. D. (2009). The virtual census: Representations of gender, race and age in video games," New Media \& Society, 11(5), 815-34.

Wilson, B. (2006). Ethnography, the Internet, and youth culture: Strategies for examining social resistance and "online-offline" relationships. Canadian Journal of Education/Revue Canadienne de l'Éducation, 307-28. 